\title{
Dynamic Inefficiency in an Overlapping Generation Economy with Pollution and Health Costs*
}

\author{
María-José Gutiérrez ${ }^{\dagger}$ \\ MacLab and DFAEII - University of the Basque Country \\ March 2008
}

\footnotetext{
${ }^{*}$ Special thanks are due to Javier Gardeazabal and Luis A. Vicente who collaborated on the early steps of this article. I also thank to an anonymous referee, Betty Agnani, Amaia Iza and Jesús Vázquez for their valuable comments. Financial aid from the Spanish Ministry of Education and Science (SEJ2006-12793/ECON) and the Basque Government (IT-241-07 and HM-2007-1-4) is gratefully acknowledged. All errors are under my own responsibility.

${ }^{\dagger}$ Correspondence to: María-José Gutiérrez Universidad del País Vasco, Avda. Lehendakari Aguirre, 83, 48015 Bilbao, Spain. Phone: 34-94-6013786, Fax: 34-94-6017123, e-mail: mariajose.gutierrez@ehu.es.
} 
Proposed running head: OGE with Pollution and Health Costs

Correspondence to: María-José Gutiérrez. Universidad del País Vasco, Avda. Lehendakari Aguirre, 83, 48015 Bilbao, Spain. Phone: 34-94-6013786, Fax: 34-94-6017123, e-mail: mariajose.gutierrez@ehu.es.

\begin{abstract}
We analyze an overlapping generations model in which pollution arises, in an accumulatively way, from production. Householders do not care directly about the environment, but pollution leads them to incur health costs when they are elderly. We show that the presence of pollution means that the economy more likely to be dynamically inefficient. For these cases we analyze two kinds of tax scheme: one based on production taxes and the other based on capital and wage taxes. We show how to design both schemes in order to put the economy into the golden rule allocation. We also show that under the production tax scheme young and elderly agents pay less taxes (or receive more transfers) than under the production tax system.
\end{abstract}

Key Words: dynamic inefficiency, externalities, health costs, overlapping generations, pollution, taxes.

JEL Classification: D62, D91, H21, Q25. 


\section{Introduction}

The World Bank (1992, p. 44) considers that the environment affects the economy through amenity, productivity and health channels. Most of the economic literature that has addressed this issue considers only the first two channels. The amenity effect is incorporated into economic models by assuming that utility agents depend negatively on pollution, which is a side product of the production process (e.g. Balçao (2001) and Nakadu (2004)). The productivity channel considers that pollution may directly affect production technology (e.g. Grimaud (1999) and Chao and Peck (2000)) or the productivity of any input (Gradus and Smulders (1996) and Ono (2002)). The aim of this paper is to analyze the effects that pollution can produce on the economy when it affects the health of agents who are forced to spend on medical care when they are elderly.

The health effect has not often been considered in theoretical environmental models. However, it is well established from the empirical point of view that quality environment and health are positively related ${ }^{1}$ and that more protective environmental policies may generate considerable health benefits in quantitative terms. ${ }^{2}$ Several epidemiologic analyses have focused on the relationship between ambient air quality and morbidity among the elderly. For instance, Schwartz (1995) shows ozone and $\mathrm{PM}_{10}$ to be associated with increased risk of hospital admissions for pneumonia and Chronic Obstructive Pulmonary Disease for persons over age 65. Xu et al. (1998), using epidemiological studies carried out in Beijing, observe that long-term exposure to air pollution is associated with increased respiratory symptoms or bronchitis in adults. Also Pope et al. (1999) and Gold et al. (2000) find that the elderly are affected by PM through the nervous system. Evans and Smith (2005) point out that air pollution can be interpreted as a signal of the increased

\footnotetext{
${ }^{1}$ For instance, Boyce et al. (1999) find that environmental stress is associated with lower scores on a composite public health index, in a cross-sectional analysis of the 50 US states. Also Gangadharan and Valenzuela (2001) show, using 1998 data from 51 countries, show that environmental stress has a significant negative effect on health status when the environmental variable is considered endogenous in the estimation procedure.

${ }^{2}$ Alberini et al. (1997) estimate that the morbidity value associated with the reduction of the Pollution Standard Index in Taiwan is between $\$ 109$ and $\$ 262$ million. Quah and Boon (2003) estimate that the total economic cost of $\mathrm{PM}_{10}$ in Singapore is about $4.31 \%$ of the country's GDP in 1999. Ostro and Chestnut (1998) show that the annual health benefit for the USA of attaining the new standards for PM2.5 relative to 1994-1996 ambient concentration is estimated at $\$ 32$ billion. In similar research, Zaim (1999) finds that a decrease in PM10 and sulphur dioxide levels to the World Health Organization guideline in the Turkish economy would have resulted in a saving of $0.12 \%$ and $0.08 \%$ of Turkey's 1990 and 1993 GDP's, respectively.
} 
risk of mortality associated with exposure to fine particles for older adults.

From a theoretical point of view, the health effect has been analyzed by Williams $(2002,2003)$ in a static general equilibrium models. In his models pollution deteriorates health (reducing the time available for leisure) or reduces consumers' productivity (which forces expenditure on medical care). He finds that the more pollution affects consumers' health, the lower the benefits associated with pollution abatement are. We also consider that pollution deteriorates consumers' health, forcing consumers to spend on medical care. We depart from the analysis of Williams $(2002,2003)$ analysis by considering a dynamic general equilibrium model in which pollution is a stock that accumulates over time with the emissions produced by firms. This is relevant since most pollutants remain in the atmosphere for long periods (for instance the greenhouse gases causing global warming, aldicarb affecting groundwater, pollutants causing acid rain, etc.). Therefore, our model includes a dynamic structure showing a production-environmental quality trade-off that implies that whenever the production economy grows, the stock of pollution increases.

Dynamic general equilibrium models have been considered in the relevant literature to examine environmental issues. However, most of the relevant studies assume dynamic models in which agents live for many periods (possibly for ever) and, therefore, restrict their analyses to intragenerational problems. Following this approach all future impacts are treated as if they happened to current agents, ignoring the fact that society is composed of mortal individuals of different generations whose actions have consequences that outlive them. Authors such as Solow (1986) and Padilla (2002) suggest that it is useful to capture these intergenerational aspects in the economic analysis of the environment and natural resources. Moreover, there is strong empirical evidence against the idea that members of extended families are altruistically linked in the way postulated by standard infinitely lived agents models (see Altonji et al. (1992)).

Recent articles have addressed intergenerational environmental issues using overlapping generation models (OGM). ${ }^{3}$ However, a recent article by

\footnotetext{
${ }^{3}$ John and Pecchenino (1994) analyze the potential conflict between economic growth and the maintenance of environmental quality in a context where consumption degrades the environment. Using the same model John et al. (1995) and Ono (1996, 2002) examine the optimal tax policies that must be implemented by a long-lived government which lasts longer than a typical agent of the economy, in order to internalize the intergenerational externalities produced by competitive behavior. Guruswamy et al. (1997) analyze the relationship between resource depletion and pollution. Bovenberg and Heijdra (1998) study the effects of environmental taxation within an OGM in which the quality of the environment is considered as a durable consumption good. Howarth and Norgaard (1992) and Howarth (1998) analyze climate change in an OGM framework. Jouvet et al. (2000)
} 
Pautrel (2007) is the only one that considers an a dynamic general equilibrium model with an overlapping framework where the health channel is the link between the environmental pollution and the economy. In particular, he assumes that a better health status makes workers more productive. In this context, Pautrel shows that active environmental policies are more likely to promote long-run growth when health is very sensitive to pollution.

Our paper is closely related to this literature. We also focus on intergenerational environmental issues and use an OGM to examine the effects that pollution can produce on the economy. However we differ from Pautrel (2007) in two essential aspects. First, we consider that pollution affects the health of agents, who are forced to expend on medical care when they are elderly, rather than affecting the productivity of workers ${ }^{4}$. Second, we do not analyze long-run growth effects. We focus rather on optimal taxation and show how to design tax schemes in order to put the economy into efficient allocations.

Our main finding is that the presence of pollution makes it more likely that competitive equilibrium will be dynamically inefficient. In particular, we show that if the economy accumulates capital above what we define as the super golden rule ratio, there are other allocations where no generation is worse off and some are better off. For those cases, we analyze two kinds of tax schemes. One scheme is based on taxes on production and the other on taxes on capital and wages. We show that if both schemes are designed to place the economy in the golden rule allocation, then young and elderly agents pay less taxes (or receive more transfers) under the production scheme than under the capital-wage tax system. Since the article focuses on the long-term health cost that each generation can expect to pay over its finite lifetime, some numerical examples of the optimal taxes schemes are simulated, with the economy being calibrated assuming that each generation lasts for 30 years.

The rest of the article is organized as follows. Section 2 presents the model. The stationary competitive equilibrium is characterized in Section 3. Section 4 focuses on optimal allocations. In Section 5 optimal tax scheme designs are presented and some numerical examples are simulated. Section 6 concludes.

construct an OGM model that includes a pollution externality in which individuals are altruistically linked to their offspring. Ono and Maeda (2001, 2002) analyze the effects of population aging on economic growth and the environment.

${ }^{4}$ This simplification of the relationship between pollution and health allows us to keep the analysis within tractable terms. This approach can be considered reasonable given that we are interested in obtaining qualitative results focused on the inherent inefficiencies arising from pollution. 


\section{The model}

Consider a two-period OGM with production. A new generation of $N_{t}$ agents is born at each period $t=1,2, \ldots$ The population grows at a constant rate, $n$, i.e. $N_{t}=N_{t-1}(1+n)$. The preferences of an agent born in period $t$ are represented by the following utility function $u\left(c_{1, t}\right)+\frac{1}{1+\theta} u\left(c_{2, t+1}\right)$, where $c_{1, t}$ and $c_{2, t+1}$, represent consumption in young and old age, respectively and $\theta$ is the subjective discount rate of the agent. We assume that $u^{\prime}>0$ and $u^{\prime \prime}<0$.

Each agent is endowed with one unit of labor when she is young and supplies it to firms inelastically. The agent receives a wage, $w_{t}$, which is used for consumption in the first period, $c_{1, t}$, and for saving, $s_{t}$. Since no income is earned in old age, all agents are savers, i.e. $s_{t}>0$. This saving is inelastically supplied to firms which pay $\left(1+r_{t+1}\right) s_{t}$ to the agent when she is old. The agent divides her saving in old age between consumption, $c_{2, t+1}$, and pollution costs.

We assume that the pollution costs faced by the older generation depend on the current level of the stock of pollution. Formally, we define $H\left(E_{t}\right)$ as the total amount paid by elderly agents living in period $t$ as pollution costs, where $E_{t}$ is the stock of pollution. ${ }^{5}$ For the sake of simplicity, we assume that $H_{t}=\xi E_{t}$, therefore the pollution costs paid by an elderly agent born at period $t-1$ can be expressed as $(1+n) \xi e_{t}$, where $e_{t}=E_{t} / N_{t}$. This formalization implies the pollution costs paid by each elderly agent depends upon the stock of pollution and the number of elderly agents. One possible interpretation of this assumption is that pollution results in illness that requires new medical research, treatments and hospital equipment; this may imply that pollution costs in each period act as a fixed cost for society. ${ }^{6}$ From now on we refer to these pollution costs as health costs.

Firms behave perfectly competitively and maximize profits. They use capital, $K$, and labor, $N$, as inputs with a standard production function $F\left(K_{t}, N_{t}\right)$ that exhibits constant returns to scale. This implies that production can be expressed in per worker terms as $f\left(k_{t}\right)$, where $k_{t}=K_{t} / N_{t}$. We assume that $f^{\prime}>0$ and $f^{\prime \prime}<0$. Capital stock depreciates at a constant rate $0 \leq \lambda \leq 1$

\footnotetext{
${ }^{5}$ In a static general equilibrium model, Williams (2002) considers that pollution may affect the health of the population either by causing the representative agent to spend time sick (reducing the time available for labor) or by forcing expenditure on medical care. We following this second approach.

${ }^{6}$ One could assume that most of the health damage from air pollution comes in the form of premature mortality. We do not consider this possibility here; in fact, we could take the pollution costs paid by elderly agents as being enough to guarantee that agents live two periods.
} 
The stock of pollution in the current period, $E_{t}$, is determined by a proportion of the past pollutant stock, $E_{t-1}$, plus the new emissions which are proportional to current production ${ }^{7}$. Therefore, the dynamics of the stock of pollution can be expressed as

$$
E_{t}=(1-\delta) E_{t-1}+\alpha F\left(K_{t}, N_{t}\right),
$$

where the parameter $0 \leq \delta \leq 1$ denotes the rate of decay. This parameter can be interpreted as the rate of natural purification of pollutants from the environment per period. Note that $\delta=1$ means that pollution is not an accumulative process. In this case the health costs of an elderly agent depend exclusively on production in that period. Parameter $\alpha>0$ represents the cleanness of the technology used to produce; the lower $\alpha$ is the cleaner the technology is ${ }^{8}$.

Notice that the only way to abate pollution by a choice is by reducing capital since labor is inelastically supplied and the population increases at an exogenous constant rate. Therefore, agents can reduce pollution by selecting consumption levels which implies reducing savings and capital accumulation.

\section{Competitive Equilibrium}

In the model described above, a dynamic competitive equilibrium is a sequence of $\left\{k_{t}, c_{1, t}, c_{2, t}, w_{t}, r_{t}, s_{t}, e_{t}\right\}_{t=0}^{\infty}$ such that, for any given $k_{0}$ and $e_{0}$, agents maximize utility, firms maximize profits and markets clear.

The representative agent born in period $t$ maximizes her utility function with respect to young and old consumption, taking wages, interest rates and the stock of pollution as given. This problem can be set out as follows

$$
\begin{gathered}
\underset{\left\{c_{1, t}, c_{2, t+1}\right\}}{\operatorname{Max}} u\left(c_{1, t}\right)+\frac{1}{1+\theta} u\left(c_{2, t+1}\right), \\
\text { s.t. }\left\{\begin{array}{l}
c_{1, t}+s_{t}=w_{t}, \\
c_{2, t+1}+(1+n) \xi e_{t+1}=\left(1+r_{t+1}\right) s_{t} .
\end{array}\right.
\end{gathered}
$$

Notice that the health costs are modeled as withdrawals from savings, which implies a reduction in consumption in old age.

The first-order condition associated with the agent's optimization problem, (2)-(3), is

$$
(1+\theta) u^{\prime}\left(c_{1, t}\right)=\left(1+r_{t+1}\right) u^{\prime}\left(c_{2, t+1}\right) .
$$

\footnotetext{
${ }^{7}$ The results of the model do not change qualitatively if current production directly affects the future stock of pollution instead of the current one.

${ }^{8}$ This equation differs from John and Pecchenino (1994) and John et al. (1995) who consider a model where consumption (rather than production) degrades the environment.
} 
This equation states that the representative agent chooses consumption such that the marginal rate of substitution between current and future consumption is equal to the marginal rate of transformation. This optimal condition and the restrictions, (3), implicitly define saving as a function of wages, interest rates and pollution; it also depends upon the subjective discount rate parameter, $\theta$, and the marginal private costs of pollution, $\xi$,

$$
s_{t}=s\left(w_{t}, r_{t+1}, e_{t+1} \mid \theta, \xi\right) .
$$

It easy to show that the saving function is characterized as follows,

$$
\begin{aligned}
s_{w} & \equiv \frac{\partial s_{t}}{\partial w_{t}}=\frac{(1+\theta) u^{\prime \prime}\left(c_{1, t}\right)}{\Delta} \in(0,1), \\
s_{e} & \equiv \frac{\partial s_{t}}{\partial e_{t+1}}=\frac{\left(1+r_{t+1}\right)(1+n) \xi e_{t+1} u^{\prime \prime}\left(c_{2, t+1}\right)}{\Delta}>0, \\
s_{r} & \equiv \frac{\partial s_{t}}{\partial r_{t+1}}=-\frac{u^{\prime}\left(c_{2, t+1}\right)+\left(1+r_{t+1}\right) s_{t} u^{\prime \prime}\left(c_{2, t+1}\right)}{\Delta} \gtrless 0, \\
s_{\theta} & \equiv \frac{\partial s_{t}}{\partial \theta}=\frac{u^{\prime}\left(c_{1, t}\right)}{\Delta}<0, \\
s_{\xi} & \equiv \frac{\partial s_{t}}{\partial \xi}=\frac{\left(1+r_{t+1}\right)(1+n) e_{t+1} u^{\prime \prime}\left(c_{2, t+1}\right)}{\Delta}>0 .
\end{aligned}
$$

where $\Delta=(1+\theta) u^{\prime \prime}\left(c_{1, t}\right)+\left(1+r_{t+1}\right)^{2} u^{\prime \prime}\left(c_{2, t+1}\right)<0$.

We obtain the standard OGM results for wages and interest rates. If wages increase, the agent saves part of the increase for future purchases. On the other hand, an increase in interest rates may increase or decrease saving depending on the extent of the substitution, income and wealth effects. If the intertemporal elasticity of substitution for consumption is high enough then $s_{r}>0$. In the particular case of a utility function with a constant intertemporal elasticity of substitution, that is

$$
u\left(c_{1 t}, c_{2, t+1}\right)=\frac{c_{1, t}^{1-\epsilon}-1}{1-\epsilon}+\frac{1}{1+\theta}\left(\frac{c_{2, t+1}^{1-\epsilon}-1}{1-\epsilon}\right),
$$

the expression for $s_{r}$ can be rewritten as

$$
s_{r}=\frac{\left[1+(1+n) \frac{\xi e_{t+1}}{c_{2, t+1}}\right]-\frac{1}{\epsilon}}{\Delta},
$$

which is positive (negative) whenever the intertemporal elasticity of substitution, $1 / \epsilon$, is larger (lower) than $1+(1+n) \frac{\xi e_{t+1}}{c_{2, t+1}} \cdot{ }^{9}$

\footnotetext{
${ }^{9}$ This result can be generalized to any utility function with the regular properties. In
} 
We also obtain that an increase in the next period stock of pollution implies that agents save more because they will face higher health costs when elderly. With respect to the parameters affecting the saving function, we obtain the expected results. The more patient the agent is (i.e. the lower $\theta$ is) and the larger her marginal private cost of pollution is, the larger savings are.

Firms maximize profits and hire labor and capital until their marginal products equal their factor prices. Given the constant return to scale production function assumed, these conditions can be expressed as

$$
\begin{aligned}
w_{t} & =f\left(k_{t}\right)-f^{\prime}\left(k_{t}\right) k_{t}, \\
r_{t} & =f^{\prime}\left(k_{t}\right)-\lambda .
\end{aligned}
$$

The market clears when total investment equals total savings. In per worker terms, this means

$$
(1+n) k_{t+1}=s\left(w_{t}, r_{t+1}, e_{t+1}\right) .
$$

Substituting equations (5) and (6 ) into this last equation, we obtain

$$
(1+n) k_{t+1}=s\left[f\left(k_{t}\right)-f^{\prime}\left(k_{t}\right) k_{t}, f^{\prime}\left(k_{t+1}\right)-\lambda, e_{t+1}\right]
$$

which is a nonlinear dynamic equation relating the two state variables of the model, $k$ and $e$. The other relationship between the state variables is given by the environmental equation, (1), which in per worker terms can be expressed as

$$
e_{t+1}=\frac{1-\delta}{1+n} e_{t}+\alpha f\left(k_{t+1}\right) .
$$

Equations (7) and (8) form a system of first-order nonlinear difference equations in $k$ and $e$. The solution of this system characterizes the competitive equilibrium paths for capital and pollution, $\left\{k_{t}, e_{t}\right\}_{t=1}^{\infty}$, given the initial values of the state variables, $k_{0}$ and $e_{0}{ }^{10}$. Once those paths are known $\left\{c_{1, t}, c_{2, t}, s_{t}, w_{t}, r_{t}\right\}_{t=1}^{\infty}$ can be obtained using (3)-(6).

the standard OGM without health costs, an intertemporal elasticity of substitution, $1 / \epsilon$, larger than one is a necessary and sufficient condition for $s_{r}>0$. However, in this version of the model, the threshold for guaranteeing a positive $s_{r}$ is greater than one.

${ }^{10}$ Since capital is essential for production, $k_{0}$ must be positive. If $k_{0}=0$ the young agents in the initial generation would have no income and consumption would remain zero forever. However $e_{0}$ may be zero. 


\subsection{The Steady State}

A steady state equilibrium is an allocation where capital and pollution per worker ratios are stationary ${ }^{11}$, i.e. $\bar{k}$ and $\bar{e}$ are such that

$$
\begin{aligned}
(1+n) \bar{k} & =s\left[f(\bar{k})-f^{\prime}(\bar{k}) \bar{k}, f^{\prime}(\bar{k})-\lambda, \bar{e}\right] \\
\bar{e} & =\frac{1+n}{n+\delta} \alpha f(\bar{k}) .
\end{aligned}
$$

The following proposition characterizes the comparative static behavior of the steady state of this model.

Proposition 1 If $(1+n)-s_{r} f^{\prime \prime}(\bar{k})+s_{w} f^{\prime \prime}(\bar{k}) \bar{k}-s_{e} \frac{1+n}{n+\delta} \alpha f^{\prime}(\bar{k})>0$ then the steady state associated with the dynamic system, (7)-(8), is a sink. Under this condition changes in the parameters of the model affect the steady state value of $\bar{k}$ and $\bar{e}$ as follows:

$$
\begin{aligned}
& \partial \bar{k} / \partial \theta<0, \quad \partial \bar{k} / \partial n<0, \quad \partial \bar{k} / \partial \delta<0, \quad \partial \bar{k} / \partial \alpha>0, \quad \partial \bar{k} / \partial \xi>0 \\
& \partial \bar{e} / \partial \theta<0, \quad \partial \bar{e} / \partial n<0, \quad \partial \bar{e} / \partial \delta<0, \quad \partial \bar{e} / \partial \alpha>0, \quad \partial \bar{e} / \partial \xi>0 .
\end{aligned}
$$

Furthermore, if the saving function is an increasing (decreasing) function of the interest rate, then, $\partial \bar{k} / \partial \lambda<0 \quad(>0)$, and $\partial \bar{e} / \partial \lambda<0 \quad(>0)$.

Proof. See Appendix.

Notice that in our set up we have two initial conditions; the characteristics of our problem lead us to assume that the initial stocks of capital and pollution, $k_{0}$ and $e_{0}$, are known. Therefore, we are interested in having a sink steady state in such a way that whatever the initial conditions are, the steady state can be reached. If the steady state were a saddle-path ${ }^{12}$, only one of the two state variables could be predetermined at the initial period: the other has to be determined to be sure that the solution is along the unique saddle path.

We can see that the results of the standard Diamond's model (1965) still hold when we have a pollution externality such as the one presented in this model. On the one hand, we observe that economies with high population growth rates have lower levels, in per worker terms, of capital

\footnotetext{
${ }^{11}$ Stationary paths are called golden aged paths by some authors (Diamond (1965), Phelps(1965)). We focus on stationary paths because this allows for direct comparison between our results and others based on OGM (for instance John et al. (1995) or Ono (1996)).

${ }^{12}$ If $(1+n)-s_{r} f^{\prime \prime}(\bar{k})+s_{w} f^{\prime \prime}(\bar{k}) \bar{k}-s_{e} \frac{1+n}{n+\delta} \alpha f^{\prime}(\bar{k})<0$ and $\Psi=1+n-s_{r} f^{\prime \prime}(\bar{k})-$ $s_{e} \alpha f^{\prime}(\bar{k})>0$, then the steady state associated with the dynamic system, (7)-(8), is a saddle path instead of a sink.
} 
and pollution. The intuition is clear, if the population grows faster, a greater part of output has to be destined for consumption, and therefore less for investment in future capital and pollution (in per worker terms). This result on pollution seems counterintuitive at first glance. Notice however that the stock of pollution, $E_{t}=e_{t} N_{t}$, in the steady state always grows at the same rate as the population, $n$. This means that higher population growth rates imply that the total stock of pollution grows faster. On the other hand, when saving is an increasing function of the interest rate $^{13}$, economies with a high capital depreciation rate accumulate less capital and pollution than those with a low depreciation rate, because a higher capital depreciation rate results in a lower interest rate, and therefore lower savings, capital and pollution.

Relating to the parameters associated with the externality introduced in the model, our characterization of the steady state shows that the more severe the pollution problem is for the economy the higher the capital and pollution ratios are. This can be observed through the parameters, $\delta, \alpha$ and $\xi$.

For instance, a lower rate of natural purification of pollutants from the atmosphere, $\delta$, implies a higher future stock of pollution for any given stock of capital, and therefore a higher health cost faced by elderly agents. This larger future costs makes agents save more for old age, which implies that society accumulates more capital and degrades the environment more. Likewise if the technology used to produce becomes dirtier (i.e. $\alpha$ higher), new emissions of pollutants are higher for any stock of pollution, and so are health costs. This results in higher savings, capital and pollution. The intuition is the same for the marginal private cost of pollution, $\xi$; a higher value for this parameter induces higher savings because it makes agents pay higher health costs for any stock of pollutant. This leads capital and pollution stocks to increase. It is worth mentioning that all these results depend crucially upon the assumption that there is not any other alternative channel for reducing pollution other than to accumulate less capital by reducing savings. ${ }^{14}$

These results differ in some terms from those obtained by John et al. (1995), who analyze an OGM in which consumption degrades the environment and the government may improve environmental quality by levying taxes on young generation. One of their results is that economies

\footnotetext{
${ }^{13}$ Savings depend positively on interest rate when the substitution effect is greater than the sum of the income and wealth effects. A high enough intertemporal elasticity of substitution for consumption guarantees $s_{r}>0$ (See footnote 9 ).

${ }^{14}$ We may include the possibility of abatement by using part of the young wealth to invest in improving the quality of the atmosphere. We belive that if this possibility is excluded the results of the model are clearer and can be interpreted more straightforwardly.
} 
in which consumption causes greater environmental degradation accumulate less capital. Our result goes in the opposite direction, showing that economies in which production causes higher environmental degradation accumulate more capital. This is so because in John et al.'s model agents pay taxes to maintain environmental quality when they are young and therefore an increase in degradation reduces their savings for the future; however, in our model, higher environmental degradation increases health costs, which are paid in the old age, so agents have to increase savings and therefore capital.

\section{Efficiency}

It is well known that in the standard OGM without externalities the competitive equilibrium is, in general, not Pareto optimal (Diamond (1965)). The intuition for this result is clear. In an OGM intertemporal trades are restricted because economic agents have a limited planning horizon and it may be the case that their decisions are not efficient. In this OGM context, Phelps (1965) defines the golden rule capital ratio as the capital ratio that maximizes consumption among all paths in which capital grows at a constant rate (i.e. in which the capital ratio is constant). He proves that any competitive growth economy whose stationary capital ratio exceeds the golden rule level is dynamically inefficient in the sense that there exists another stationary allocation (with a lower capital ratio) where no generation is worse off and at least some generations are better off. We expect the introduction of any negative pollution externality in the OGM to extend the scope of this feature.

We know that any allocation selected by an idealized central planner capable of caring not only about the current generation but also about future generations is optimal in the Pareto sense (see Blanchard and Fisher (1989) pages 97-104). If the current period is $t=0$, the central planner problem can be set out as follows ${ }^{15}$ :

$$
\begin{aligned}
& \underset{\left\{k_{t+1}, c_{1, t}, c_{2, t}\right\}_{t=0}^{\infty}}{\operatorname{Max}} \frac{1}{1+\theta} u\left(c_{2,0}\right)+\sum_{t=0}^{\infty} \frac{1}{(1+R)^{t+1}}\left[u\left(c_{1, t}\right)+\frac{1}{1+\theta} u\left(c_{2, t+1}\right)\right], \\
& \text { s.t. }\left\{\begin{array}{l}
F\left(K_{t}, N_{t}\right)=N_{t} c_{1, t}+N_{t-1} c_{2, t}+K_{t+1}-(1-\lambda) K_{t}+H\left(E_{t}\right), \\
E_{t}=(1-\delta) E_{t-1}+\alpha F\left(K_{t}, N_{t}\right),
\end{array}\right.
\end{aligned}
$$

\footnotetext{
${ }^{15}$ We are taking the standard approach in the literature, in which the central planner discounts the future at a constant rate. See Karp (2005) for an approach where long-lived environmental problems are analyzed under hyperbolic discounting i.e. assuming that the ability to make distinctions diminishes for more distant events..
} 
where $R \geq 0$ is the subjective discount rate of the planner. If the planner cares less about future generations, $R$ is strictly positive and if she cares equally about all generations, $R$ is zero ${ }^{16}$. The first restriction of problem (11) is the resource constraint of the economy in period $t$, which means that the total supply of goods is allocated to the consumption of the young and old, to health expenditures and to providing for the next period's capital stock. The second restriction indicates the dynamics of the stock of pollution.

The first order condition of the planner's maximization problem can be summarized in the following equations,

$$
\begin{aligned}
(1+\theta) u^{\prime}\left(c_{1, t}\right)= & (1+R)(1+n) u^{\prime}\left(c_{2, t}\right), \\
(1+\theta) \frac{u^{\prime}\left(c_{1, t}\right)}{u^{\prime}\left(c_{2, t+1}\right)}= & {\left[(1-\alpha \xi) f^{\prime}\left(k_{t+1}\right)+(1-\lambda)+(1-\delta)\right]-} \\
& \frac{u^{\prime}\left(c_{2, t+2}\right)}{u^{\prime}\left(c_{1, t+1}\right)} \frac{1-\delta}{1+\theta} \frac{f^{\prime}\left(k_{t+1}\right)}{f^{\prime}\left(k_{t+2}\right)}\left[f^{\prime}\left(k_{t+2}\right)+(1-\lambda)\right],
\end{aligned}
$$

Equation (12) represents intergenerational optimal consumption allocations and states that the marginal rate of substitution, from the point of view of the central planner, between consumption by the young and consumption by the elderly must be equal to the rate of transformation, $(1+n)$. Equation (13) is the intragenerational optimal consumption condition and indicates how consumption for each generation is chosen.

Evaluating these conditions and the restrictions of the problem in the steady state, we have the system that defines the efficient steady state, $\left(\bar{k}^{E}, \bar{c}_{1}^{E}, \bar{c}_{2}^{E}, \bar{e}^{E}\right)$, for a given planner's discount rate,

$$
\begin{aligned}
(1+\theta) u^{\prime}\left(\bar{c}_{1}^{E}\right) & =(1+R)(1+n) u^{\prime}\left(\bar{c}_{2}^{E}\right), \\
{\left[1-\frac{\alpha \xi(1+n)(1+R)}{(1+n)(1+R)-(1-\delta)}\right] f^{\prime}\left(\bar{k}^{E}\right) } & =(1+n)(1+R)-(1-\lambda), \\
f\left(\bar{k}^{E}\right) & =\bar{c}_{1}^{E}+\frac{\bar{c}_{2}^{E}}{1+n}+(n+\lambda) \bar{k}^{E}+h\left(\bar{e}^{E}\right), \\
\bar{e}^{E} & =\frac{1+n}{n+\delta} \alpha f\left(\bar{k}^{E}\right),
\end{aligned}
$$

where superscript ${ }^{E}$ stands for efficient.

\footnotetext{
${ }^{16}$ Note that if $R$ is non-positive the sum of the utilities does not converge. However, we consider the borderline case, $R=0$, because it is possible in this case to discuss optimality using the overtaking criterion (Burmeister, 1980), which essentially states that path $A$ overtakes path $B$ if there exists a finite $t^{*}$ such that the present value of the future utilities associated with path $A$ up to time $t^{*}$ exceeds that associated with path $B$ up to $t^{*}$, and that inequality remains in the same direction for all $t>t^{*}$. A path is optimal if it overtakes all other paths.
} 
Condition (14) shows how the planner allocates consumption intergenerationally. Notice that when all generations are treated equally by the planner (i.e. $R=0$ ), this is the allocation that would arise if consumption decisions were made individually based on an interest rate equal to the growth rate of the population (compare (14) with (4)). The intuition is clear. In stationary equilibria, a switch of one unit of consumption of an agent from her youth to her old age is equivalent to removing one unit of consumption from each of the young agents in the living generation and giving the total amount to the contemporary older generation, of whom there are $n$ percent fewer members. Equation (15) indicates that the central planner recognizes that current production degrades the future environment, affecting future health costs faced by agents; therefore, the discounted marginal net benefit of an extra unit of capital (left-hand side) equates to its discounted marginal cost (right-hand side $)^{17}$. Equations (16) and (17) are the resource constraint of the economy and the stock of pollution in the steady state, respectively.

It is interesting to characterize the efficient solution for the case of a zero social discount rate, i.e. $R=0$, since this is the discount used in empirical studies such as the Stern Report on Climate Change. From the theoretical point of view, this solution is called the golden rule. Considering equation (15), we can see that the optimal stationary capital ratio for the golden rule case is given by,

$$
\left[1-\frac{\alpha \xi(1+n)}{n+\delta}\right] f^{\prime}\left(\bar{k}^{G}\right)=n+\lambda,
$$

where superscript ${ }^{G}$ stands for golden rule allocation. Diamond (1965) shows that in the standard OGM without pollution externalities any economy whose stationary capital ratio exceeds the golden rule level is dynamically inefficient in the sense that there exists another stationary allocation where no generation is worse off and at least some generations are better off. The following example shows that, in general, this statement is not true when there are pollution externalities.

Example 1 Consider an economy where each period covers 30 years with the following annual parameter values ${ }^{18}: n=0.01, \lambda=0.05, \delta=0.005$,

\footnotetext{
${ }^{17}$ Notice that in order to have a positive $\bar{k}^{E}$ it is necessary that $1-\frac{(1+n)(1+R)}{(1+n)(1+R)-(1-\delta)} \alpha \xi>$ 0 . This feasibility condition establishes that, from the central planner's point of view, the discounted health costs associated with one unit of production should be less than that unit; otherwise net output will be negative.

${ }^{18}$ It is easy to show that if each period covers 30 years, the parameter values for each period are such that $\left(1+n^{*}\right)=(1+n)^{p},\left(1-\lambda^{*}\right)=(1-\lambda)^{p},\left(1-\delta^{*}\right)=(1-\delta)^{p}$, $\alpha^{*}=\alpha \delta^{*} / \delta$ and $\left(1+R^{*}\right)=(1+R)^{p}$ where variables without ${ }^{*}$ are the annual parameter values and $p=30$.
} 


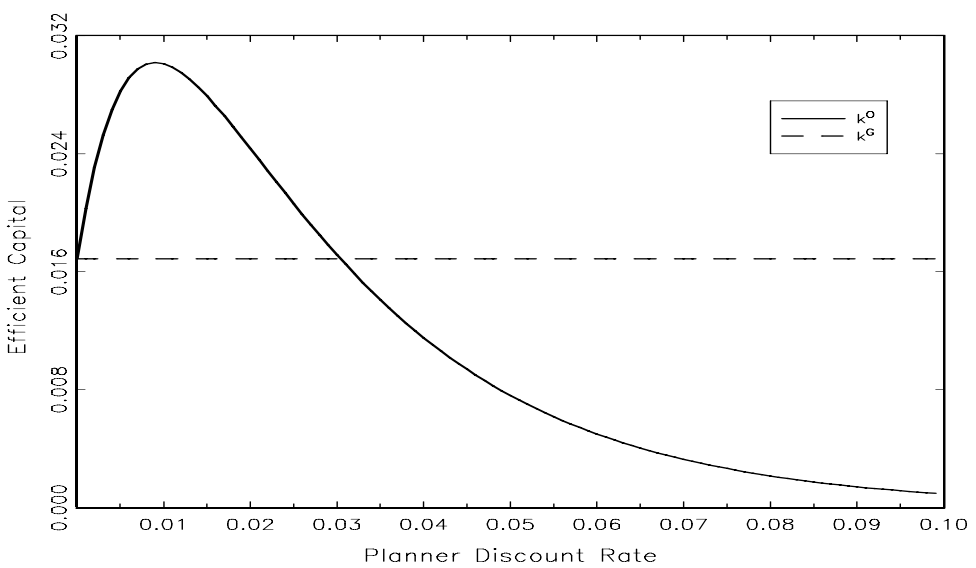

Figure 1: Efficient capital and planner's discount rate

$\alpha=1, \xi=0.01$. The production function is $f\left(k_{t}\right)=k_{t}^{\beta}$ with $\beta=0.35$. Then, when the central planner's annual discount rate is lower than 3\%, the efficient stationary capital ratio is larger than that associated with the golden rule.

The result of this example can be seen in Figure 1 where the efficient stationary capital ratio, $k^{E}$, is plotted as a function of the subjective annual discount rate of the planner, $R$. It is clear that the efficient steady state capital stock is not monotonically decreasing in the central planner's discount rate. In particular, when the central planner's annual discount rate is lower than $3 \%$, the efficient capital ratio is higher than that associated with the golden rule. This can be generalized in the following lemma.

Lemma 1 If the pollution externality is such that $\alpha \xi>\frac{(n+\delta)^{2}}{(1+n)^{2}-(1-\delta)(1-\lambda)}$, then there are always efficient capital ratios that exceed the golden rule capital ratio. Otherwise, the maximum efficient capital ratio is given by the golden rule allocation.

Proof. See Appendix.

The intuition for this result is as follows. The discount rate affects the steady state capital stock through two channels. The first, classic, channel 
says that a lower planner's discount rate implies higher weights attached to the welfare of future generations, and thereby higher savings that transfer higher capital stock to the future. The second channel is based on the pollution externality and contrasts with the effects of the first channel. A lower planner's discount rate implies lower pollution levels transferred to future periods, but since pollution is linked to the capital stock, it also implies lower capital stock levels transferred as well. The relative strengths of the two channels determines whether a decrease in the planner's discount rate implies higher or lower capital stock. In particular, we show that if the pollution externality is weak (i.e. if $\alpha \xi$ is small), or if the pollution decay rate is large ( $\delta$ close to one), then the classic conclusion holds that a decrease in the planner's discount rate implies an increase in the capital stock. ${ }^{19}$

It is well known that without the pollution externality all generations of an economy whose stationary capital ratio exceeds the golden rule capital ratio may be better off if the stock of capital is reduced once and forever and the consumption of current elderly agents increases by the same amount (Blanchard and Fischer (1989), page 102-104). In general, this kind of reallocation of capital over time only works in the presence of pollution externalities for economies whose capital ratio is high enough. In particular, we can find a stationary capital ratio benchmark such that any economy exceeding it is dynamically inefficient for any $\delta$. We call this benchmark the super golden rule capital ratio, and it is defined such that

$$
f^{\prime}\left(k^{S G}\right)=\frac{n+\lambda}{1-\alpha \xi}
$$

where superscript ${ }^{S G}$ stands for super golden rule allocation. It is easy to show that $k^{S G}>k^{G}$ for $\delta<1$ and $k^{S G}=k^{G}$ for $\delta=1$. The following proposition formalizes this result.

Proposition 2 Any economy with pollution externalities whose stationary capital ratio exceeds the super golden rule capital ratio, $k^{S G}$, is dynamically inefficient.

\section{Proof. See Appendix}

The main reason why the Blanchard and Fischer reallocation of capital does not work in our model is because pollution is an accumulative process. Observe that we have two stock variables in our model (capital and pollution)

\footnotetext{
${ }^{19}$ Observe that when $\delta=1$, the condition for having efficient capital ratios larger than the golden rule capital ratio becomes $\alpha \xi>1$, which is not possible because then $\bar{k}^{E}$ becomes negative (see footnote 17).
} 
and this makes the model work in some peculiar ways. Suppose that we are in a stationary equilibrium and at some period $\tau$, the capital ratio is changed once and for ever. Then the economy will not be in stationary equilibrium from that period on. The economy will need a number of periods to make the pollution stock stationary; and that the number will depend on the rate of natural purification of the pollutant from the environment, $\delta$. Only when $\delta=1$, i.e. when emissions stay in the environment for just one period, does a change in the capital ratio of the once and for ever type makes the economy move immediately from one stationary equilibrium to another. Because of this, Diamond's result (1965) still holds in the presence of a negative production externality if pollution is not an accumulative process $(\delta=1)$. Notice that Proposition 2 also shows this case because the super golden rule capital ratio coincides with the golden rule in the case of $\delta=1$.

Figure 2 summarizes these results. Proposition 2 shows that any economy with a capital ratio greater than $k^{S G}$ is dynamically inefficient. Let $k^{M A X}$ denote the maximum efficient capital ratio among all the solutions of the central planner's optimization problem, $(11),{ }^{20}$ then those economies whose capital ratio is lower than $k^{M A X}$ are dynamically efficient. Lemma 1 states the conditions under which $k^{M A X}=k^{G}$. We are not able to classify economies with capital ratios in $\left(k^{M A X}, k^{S G}\right)$ in terms of efficiency. On the one hand, those economies could be dynamically efficient because the solution set of the central planner problem's, (11), may not give us the whole set of optimal allocations. Consider, for example, a planner with a subjective discount rate, $R$, that changes over time in a hyperbolic shape (see Karp (2005)). The optimization problem (11) does not take this possibility into account. On the other hand, we cannot rule out the possibility that those economies may be dynamically inefficient. The proof of Proposition 2 only shows that reducing of current investment, increasing current consumption by the same amount and keeping the future capital ratio constant over time dominates, in the Pareto sense, any allocation where the capital ratio is higher than the super golden rule level. However we cannot exclude the possibility that other kinds of reallocation of capital over time may improve some generations without worsening others for economies with capital ratios in the rank $\left(k^{M A X}, k^{S G}\right)$.

We show in Proposition 2 that any economy with a capital ratio

\footnotetext{
${ }^{20}$ In the proof of Lemma 1 , we show that $k^{M A X}$ is the capital ratio associated with the central planner's discount rate $R^{+}$. It is easy to prove that $k^{M A X}$ satisfies

$$
f^{\prime}\left(k^{M A X}\right)=\chi^{1 / 2}\left[\frac{(1-\delta)+\chi^{1 / 2}}{(1-\alpha \xi)}-(1-\lambda)\right]\left[\frac{(1-\delta)+\chi^{1 / 2}}{(1-\alpha \xi)}-(1-\delta)\right],
$$

where $\chi=(1-\delta) \alpha \xi[(1-\delta)-(1-\lambda)(1-\alpha \xi)]$ and $k^{M A X}<k^{S G}$.
} 


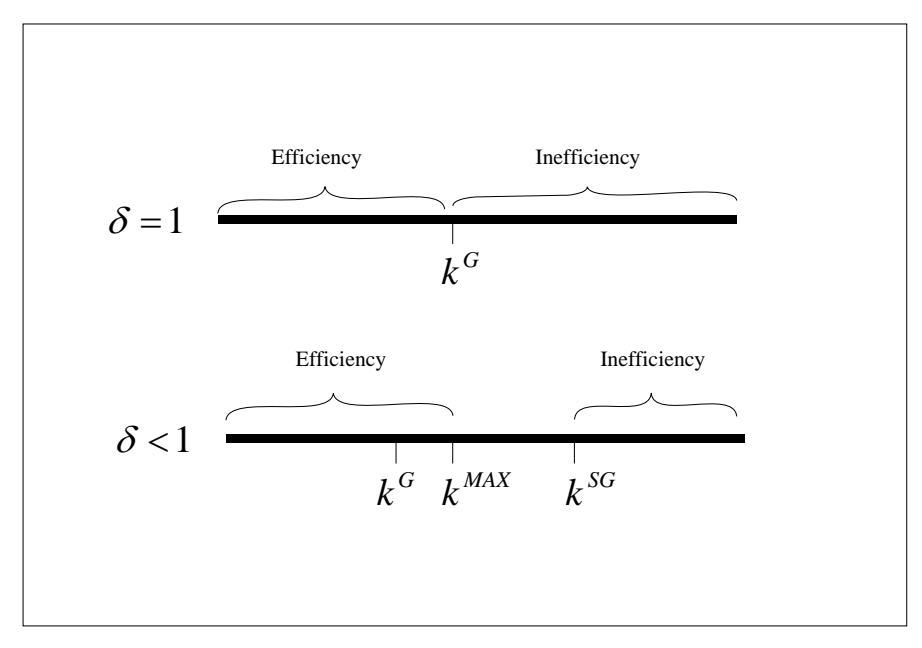

Figure 2: Ranges and capital ratios

greater than $k^{S G}$ is dynamically inefficient. It is easy to see that $k^{S G}$ is decreasing in the pollution parameters. Therefore economies with more environmental problems have a larger range of dynamically inefficient allocations. On the other hand, we show in Proposition 1 that economies with more environmental problems accumulate more capital and degrade the environment more when they act in a competitive manner. These two results allow us to formalize the following proposition.

Proposition 3 The higher the pollution externalities are, the higher the competitive stationary capital ratio is and the lower the super golden rule capital ratio is.

Proof. Pollution externalities are the result of three factors: a lower rate of natural purification of the pollutant from the atmosphere, $\delta$, dirtier production technology (i.e. a higher $\alpha$ ) and/or a higher marginal private cost of pollution, $\xi$.

It is easy to see the $\partial k^{S G} / \partial \delta=0, \partial k^{S G} / \partial \alpha<0$ and $\partial k^{S G} / \partial \xi<0$. Moreover, in Proposition 1, we prove that $\partial \bar{k} / \partial \delta<0, \partial \bar{k} / \partial \alpha>0$ and $\partial \bar{k} / \partial \xi>0$. Therefore, $\frac{\partial\left(\bar{k}-k^{S G}\right)}{\partial \delta}<0, \frac{\partial\left(\bar{k}-k^{S G}\right)}{\partial \alpha}>0$, and $\frac{\partial\left(\bar{k}-k^{S G}\right)}{\partial \xi}>0$.

\section{Tax Schemes}

In a competitive equilibrium, no generation has any incentive to consider the successive generations. Therefore, future generations suffer from past 
production which has degraded the environment. We have seen that a competitive stationary equilibrium is dynamically inefficient when the capital ratio is higher than the super golden rule allocation and also that the larger the pollution externality is the higher the likelihood of dynamic inefficiency is. This section studies how to implement tax schemes in order to achieve efficient allocations for economies whose competitive equilibrium is dynamically inefficient. In particular, we find the optimal tax schemes that place stationary competitive economies in the golden rule allocation which is the efficient allocation associated with a central planner who does not discount the future and treat all future generation equally.

\subsection{Taxes on Production}

We introduce a Pigouvian tax on production and a lump-sum tax system into our model. Let $\tau_{p}$ be a production tax paid by firms per unit of output produced and let $\tau_{y}$ and $\tau_{o}$ be lump-sum taxes levied on young and elderly agents, respectively, in any period. The government budget constraint implies that the system should be set up in such way that the following condition is satisfied

$$
\tau_{y}+\frac{\tau_{o}}{1+n}+\tau_{p} f(k)=0 .
$$

This means that at least one of the lump-sum taxes must be a transfer.

In the presence of such a tax scheme, the problem that firms must solve is

$$
\operatorname{Max}_{\left\{k_{t}\right\}_{t=0}^{\infty}}\left(1-\tau_{p}\right) f\left(k_{t}\right)-w_{t}-\left(r_{t}+\lambda\right) k_{t}
$$

for $k_{o}$ given.

And the problem faced by the representative consumer is

$$
\begin{gathered}
\underset{\left\{c_{1, t}, c_{2, t+1}\right\}_{t=0}^{\infty}}{\operatorname{Max}} u\left(c_{1, t}\right)+\frac{1}{1+\theta} u\left(c_{2, t+1}\right), \\
\text { s.t. }\left\{\begin{array}{l}
c_{1, t}+s_{t}=w_{t}-\tau_{y}, \\
c_{2, t+1}+(1+n) \xi e_{t+1}=\left(1+r_{t+1}\right) s_{t}-\tau_{o} .
\end{array}\right.
\end{gathered}
$$

In this scenario, a stationary competitive equilibrium is an allocation $\left\{\bar{k}^{C}, \bar{e}^{C}, \bar{c}_{1}^{C} \bar{c}_{2}^{C}, \bar{w}^{C}, \bar{r}^{C}, \bar{s}^{C}\right\}$ such that for a given tax scheme, $\left\{\tau_{p}, \tau_{y}, \tau_{o}\right\}$, 
satisfies

$$
\begin{aligned}
(1+\theta) u^{\prime}\left(\bar{c}_{1}^{C}\right) & =\left(1+\bar{r}^{C}\right) u^{\prime}\left(\bar{c}_{2}^{C}\right), \\
\bar{c}_{1}^{C}+\bar{s}^{C} & =\bar{w}^{C}-\tau_{y}^{C}, \\
\bar{c}_{2}^{C}+(1+n) \xi \bar{e}^{C} & =\left(1+\bar{r}^{C}\right) \bar{s}^{C}-\tau_{o}, \\
\bar{w}^{C} & =\left(1-\tau_{p}\right)\left[f\left(\bar{k}^{C}\right)-f^{\prime}\left(\bar{k}^{C}\right) \bar{k}^{C}\right], \\
\bar{r}^{C} & =\left(1-\tau_{p}\right) f^{\prime}\left(\bar{k}^{C}\right)-\lambda, \\
\bar{s}^{C} & =(1+n) \bar{k}^{C}, \\
\bar{e}^{C} & =\frac{1+n}{n+\delta} \alpha f\left(\bar{k}^{C}\right),
\end{aligned}
$$

where equations (18), (19) and (20) are from the consumer's maximization problem, equations (21) and (22) correspond to the wage and interest rate that maximize firms' profits, respectively, equation (23) comes from the market clearance condition and equation (24) indicates the relationship between the environment and the capital ratio in the steady state.

Comparing these equations with the optimal conditions defined by the golden rule allocation, we can set the optimal production tax scheme that satisfies the government budget constraint. For instance, comparing equations (18) and (12) valued at $R=0$, we see that in this competitive solution an optimal tax scheme implies $\bar{r}^{C}=n$. Taking this into account, equation (22) can be rewritten as

$$
\left(1-\tau_{p}\right) f^{\prime}\left(\bar{k}^{C}\right)=n+\lambda .
$$

If this expression is compared with the efficient condition given by equation (13) valued at $R=0$, we see that the production tax has to be set to $\tau_{p}^{*}=\frac{1+n}{n+\delta} \alpha \xi$. In other words, only if the tax production is set in this way can the competitive equilibrium can meet the efficient solution implied by the golden rule.

The following proposition shows the complete characterization of this optimal tax scheme,

Proposition 4 Economies whose stationary competitive equilibrium overaccumulates capital can achieve the optimal golden rule allocation by the following combination of production and lump-sum taxes:

$$
\begin{aligned}
\tau_{p}^{*} & =\frac{1+n}{n+\delta} \alpha \xi, \\
\tau_{y}^{*} & =\left(1-\tau_{P}^{*}\right)\left[f\left(k^{G}\right)-f^{\prime}\left(k^{G}\right) k^{G}\right]-c_{1}^{G}-(1+n) k^{G}, \\
\tau_{o}^{*} & =-\left[\tau_{p}^{*} f\left(k^{G}\right)+\tau_{y}^{*}\right](1+n),
\end{aligned}
$$


where $\tau_{o}^{*}<0$ and $\tau_{y}^{*} \leq 0(>0)$ when the presence of pollution is (is not) the only cause of capital overaccumulation.

Proof. See Appendix.

Notice that with this optimal scheme elderly agents always receive transfers. However young agents can be characterized both as tax payers and transfer receivers. The existence of two possible market failures is the reason for these two alternative situations. In those economies where the competitive equilibrium is efficient in the absence of pollution, the introduction of the environmental problem generates an inefficiency which is amended with a tax scheme where both young and elderly agents share the revenue from the tax on production. However, in those economies where the competitive equilibrium is inefficient in the absence of pollution, the introduction of the environmental problem exacerbates this inefficiency. In this case, the young agents are tax payers and transfer resources to elderly agents (who also receive the revenue from the tax on production). ${ }^{21}$

The following example illustrates an economy that may be in either of the two situations depending on the labor share parameter.

Example 2 Consider an economy where each period covers 30 years with the following annual parameter values ${ }^{22}: n=0.02, \lambda=0.04, \delta=0.005$. The utility function is logarithmic, $u\left(c_{i, t}\right)=\ln \left(c_{i, t}\right)$, with an annual subjective discount rate $\theta=0.02$. The production function is given by $f\left(k_{t}\right)=A k_{t}^{\beta}$ with $A=20$.

i) If the labor share is such that $\beta>0.2637$ then dynamic inefficiency only appears when pollution externalities are high enough. In this case young and elderly agents are transfer receivers with the production tax scheme.

ii) If the labor share is such that $\beta<0.2637$ then dynamic inefficiency appears even in absence of pollution externalities. In this case elderly agents are transfer receivers and young agents are tax payers under the production tax scheme.

Table 1 shows the optimal taxes on production under the two situations for the economy described in Example 2. On the one hand, we can see that

\footnotetext{
${ }^{21}$ Remember that the competitive equilibrium of an overlapping generation economy is not always inefficient. In a standard OGM, only those economies in which the stationary competitive capital ratio exceeds the golden rule capital ratio are dynamically inefficient.

${ }^{22}$ See footnote 18.
} 
Table 1: Optimal Taxes on Production (Example 2)

\begin{tabular}{|c|c|}
\hline \multicolumn{2}{|l|}{$\beta=0.25$} \\
\hline No pollution $(\alpha \xi=0)$ & Pollution externalities $(\alpha \xi=0.003)$ \\
\hline $\begin{array}{ll}k^{C}=4.2224 & \tau_{p}=0 \\
k^{G}=3.8722 & \tau_{y}=0.4706 \\
k^{S G}=3.8722 & \tau_{o}=-0.8525\end{array}$ & $\begin{array}{ll}k^{C}=8.5563 & \tau_{p}=0.1596 \\
k^{G}=3.0711 & \tau_{y}=0.3733 \\
k^{S G}=3.4458 & \tau_{o}=-8.3282\end{array}$ \\
\hline \multicolumn{2}{|l|}{$\beta=0.35$} \\
\hline No pollution $(\alpha \xi=0)$ & Pollution externalities $(\alpha \xi=0.003)$ \\
\hline $\begin{array}{ll}k^{C}=4.2285 & \tau_{p}=0 \\
k^{G}=8.0024 & \tau_{y}=0 \\
k^{S G}=8.0024 & \tau_{o}=0\end{array}$ & $\begin{array}{ll}k^{C}=7.2200 & \tau_{p}=0.1596 \\
k^{G}=6.1246 & \tau_{y}=-3.7654 \\
k^{S G}=6.9946 & \tau_{o}=-4.0796\end{array}$ \\
\hline
\end{tabular}

if the labor share is high, the competitive equilibrium is efficient provided there are no pollution externalities $\left(k^{C}<k^{G}\right)$. Observe that in this situation it is not necessary to implement any tax scheme (see the left lower corner case). However, when pollution affects the economy, dynamic inefficiency may appear when the externalities are high enough. ${ }^{23}$ In this case, the optimal production tax scheme consists of taxing firms and sharing out the revenue between elderly and young agents (see the right lower corner case). On the other hand, if the labor share is low, the market economy overaccumulates capital even when the economy does not exhibit pollution externalities $\left(k^{C}>k^{S G}\right)$. This inefficiency disappears with an adequate transfer from young people to elderly agents without taxing firms (see top left corner case). If the economy also suffers pollution, the overaccumulation of capital is even larger. In this state, the optimal production tax implies taxing firms; this revenue goes to increase the transfer received by elderly agents and to lower the taxes paid by young agents, although they are still net tax payers (see top right corner).

\subsection{Taxes on Capital and Wages}

Following John et al. (1995), we consider an alternative tax scheme based on taxing capital and wage incomes. In particular, we focus on two different

\footnotetext{
${ }^{23}$ In this example, if the pollution externality is such that $\alpha \xi<0.0025$, the market equilibrium is efficient because $k^{C}<k^{G}$.
} 
possibilities. Firsts, we assume that the planner levies taxes on capital and wage incomes at different rates and second, that they are taxed at the same rate.

Assume that the planner levies taxes on gross capital and wages at the rates $\tau_{k}$ and $\tau_{w}$, respectively, and let $\sigma$ be a transfer that elderly agents receive, in any period. The government budget constraint implies that the tax system should be set as follows,

$$
w \tau_{w}+\frac{(1+r) s}{1+n} \tau_{k}-\frac{\sigma}{1+n}=0
$$

Since taxes are levied on consumers, firms face the same problem as without taxes. Each representative consumer solves

$$
\begin{gathered}
\underset{\left\{c_{1, t}, c_{2, t+1}\right\}_{t=0}^{\infty}}{\operatorname{Max}} u\left(c_{1, t}\right)+\frac{1}{1+\theta} u\left(c_{2, t+1}\right), \\
\text { s.t. }\left\{\begin{array}{l}
c_{1, t}+s_{t}=w_{t}\left(1-\tau_{w}\right), \\
c_{2, t+1}+(1+n) \xi e_{t+1}=\left(1+r_{t+1}\right)\left(1-\tau_{k}\right) s_{t}+\sigma .
\end{array}\right.
\end{gathered}
$$

Under this tax scheme, a stationary equilibrium $\left\{\bar{k}^{C}, \bar{e}^{C}, \bar{c}_{1}^{C} \bar{c}_{2}^{C}, \bar{w}^{C}, \bar{r}^{C}, \bar{s}^{C}\right\}$ must satisfy

$$
\begin{aligned}
(1+\theta) u^{\prime}\left(\bar{c}_{1}^{C}\right) & =\left(1+\bar{r}^{C}\right)\left(1-\tau_{k}\right) u^{\prime}\left(\bar{c}_{2}^{C}\right), \\
\bar{c}_{1}^{C}+\bar{s}^{C} & =\bar{w}^{C}\left(1-\tau_{w}\right), \\
\bar{c}_{2}^{C}+(1+n) \xi \bar{e}^{C} & =\left(1+\bar{r}^{C}\right)\left(1-\tau_{k}\right) \bar{s}^{C}+\sigma, \\
\bar{w}^{C} & =f\left(\bar{k}^{C}\right)-f^{\prime}\left(\bar{k}^{C}\right) \bar{k}^{C}, \\
\bar{r}^{C} & =f^{\prime}\left(\bar{k}^{C}\right)-\lambda, \\
\bar{s}^{C} & =(1+n) \bar{k}^{C}, \\
\bar{e}^{C} & =\frac{1+n}{n+\delta} \alpha f\left(\bar{k}^{C}\right) .
\end{aligned}
$$

The following proposition summarizes the features of this optimal tax scheme.

Proposition 5 Dynamically inefficient economies can achieve the golden rule allocation by a combination of the following wage and capital taxes:

$$
\begin{aligned}
\tau_{k}^{*} & =\frac{(n+\lambda) \alpha \xi}{(n+\delta)-(1-\lambda) \alpha \xi}, \\
\tau_{w}^{*} & =1-\frac{c_{1}^{G}+(1+n) k^{G}}{f\left(k^{G}\right)-f^{\prime}\left(k^{G}\right) k^{G}}, \\
\sigma^{*} & =\left[\frac{c_{2}^{G}}{1+n}+\xi e^{G}-(1+n) k^{G}\right](1+n),
\end{aligned}
$$


where $\sigma^{*}>0,0 \leq \tau_{k}^{*}<1$ and $\tau_{w}^{*}<1$. Moreover $\tau_{w}^{*}>0$ provided the economy overaccumulates capital even without the presence of pollution.

Proof. See Appendix.

With this tax scheme, both young and old agents can be tax payers or transfer receivers. It is easy to show that net taxes paid by each type of agent can be expressed as

$$
\begin{aligned}
T_{y} & \equiv w \tau_{w}=\frac{c_{2}^{G}}{1+n}+\xi e^{G}-(1+n) k^{G}+k^{G}\left[f^{\prime}\left(k^{G N}\right)-f^{\prime}\left(k^{G}\right)\right] \\
T_{o} & \equiv(1+r) s \tau_{k}-\sigma=-(1+n) T_{y}
\end{aligned}
$$

where $T_{y}$ and $T_{o}$ are the net taxes paid by each young and elderly agent, respectively; and $k^{G N}$ is defined as the golden rule of the economy in the case in which there is no pollution externality, i.e. $k^{G N}$ satisfies $f^{\prime}\left(k^{G N}\right)=n+\lambda$. Notice that $\frac{c_{2}^{G}}{1+n}+\xi e^{G}-(1+n) k^{G}>0$, because we are analyzing economies that overaccumulate capital and $k^{G}\left[f^{\prime}\left(k^{G N}\right)-f^{\prime}\left(k^{G}\right)\right]<0$ is always negative. Therefore economies whose competitive equilibrium is far from the golden rule allocation and/or have a golden rule allocation that does not change much with pollution parameters will tend to have young agents as tax payers and elderly agents as transfer receivers. However, economies in which the competitive equilibrium is close to (but above) the golden rule allocation and/or the golden rule allocation is very sensitive to pollution parameters will be characterized by young agents as transfer receivers and elderly ones as tax payers ${ }^{24}$.

Continuing with the example 2, Table 2 is a prolongation of Table 1 and shows the optimal capital and wage taxes that places the market equilibrium in the golden rule allocation. Two points can be made. First, in the absence of pollution externalities, if the market allocation is dynamically inefficient the optimal capital-wage tax scheme consists of taxing young agents through income from work $\left(\tau_{w}>0\right)$ and transferring the revenue to the old agents. Second, the existence of a pollution externality increases inefficiency and increases the capital and wage tax rates.

\footnotetext{
${ }^{24}$ In fact Proposition 5 shows that a sufficient condition for having young agents as tax payers and elderly agents as transfer receivers is for that the economy to overaccumulate capital even in the absence of pollution externalities. However, the reverse is not true.
} 
Table 2: Optimal Taxes on Capital and Wages (Example 2)

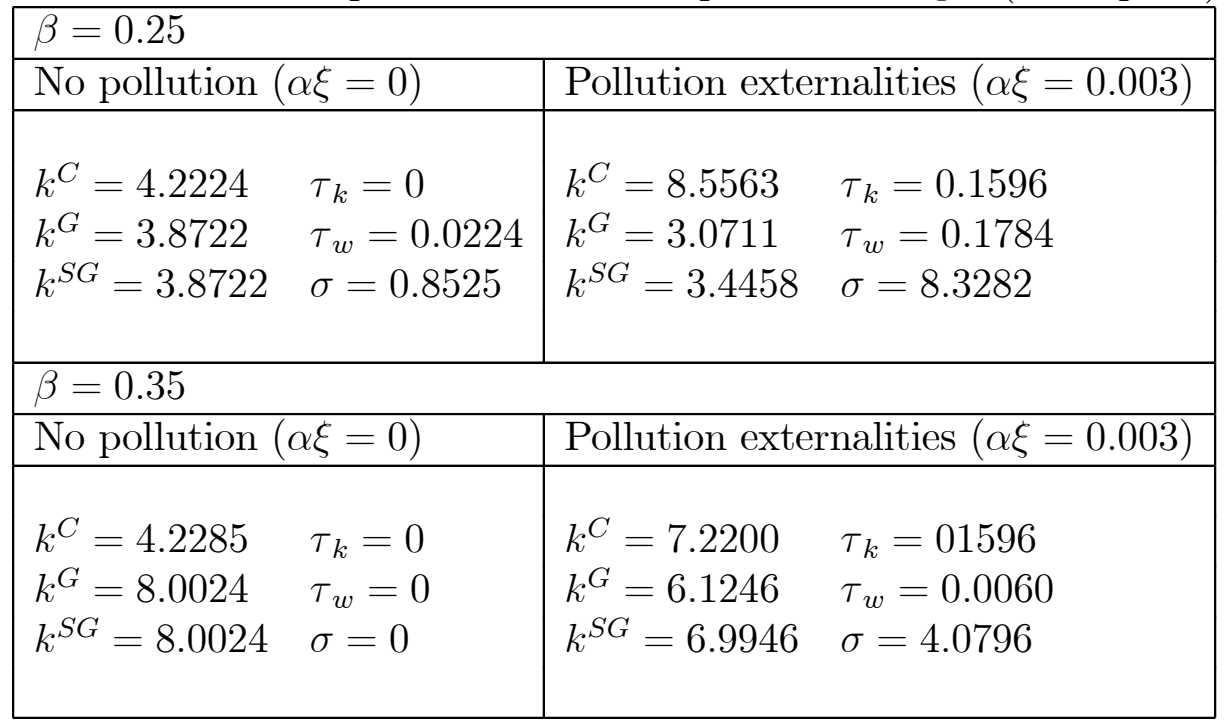

\subsection{Taxes on Production vs. Taxes on Capital and Wages}

Both the tax schemes analyzed succeed in taking the market economy to the stationary golden rule allocation. This means that from the welfare point of view, young and elderly agents are indifferent as to which tax scheme they prefer. However, we can assume that in choosing between different tax schemes agents are likely to prefer those systems in which the amount of taxes paid is lower.

Let us consider consumers as the only citizens from the electoral point of view. The following proposition shows the amount paid by each agent in both schemes analyzed.

Proposition 6 Young and elderly agents pay more taxes with the capitalwage system than with the production tax scheme.

Proof. See Appendix.

This proposition shows that consumers prefers the production tax system when the amount paid in tax is the criterion considered. Therefore the production tax scheme is superior in an electoral context in which each consumer holds one vote. This result can be considered a kind of "electoral illusion" because consumer do not take into account the taxes paid by firms with the production scheme 


\section{Conclusions}

This paper analyzes the effects that pollution can have on the economy when it affects the health of agents who are forced to spend on medical care. The health effect has not often been considered in theoretical environmental models, although it is well established from the empirical point of view that quality of environment and health are positively related.

Williams (2002) examines the economic effects of pollution when it affects consumers' health in the context of a static general equilibrium model in which pollution deteriorates the health (reducing the time available for leisure) or productivity of consumers (forcing expenditure on medical care). Unlike Williams (2000), our model is a dynamic general equilibrium model in which pollution is a stock that accumulates over time. This is relevant if we take into account that in most real environmental problems, pollutants remain in the environment for long periods (for instance the greenhouse gases causing global warming, aldicarb affecting groundwater, pollutants causing acid rain).

We use an overlapping generation framework in which different generations of agents cohabit at any given time. This model feature allows us to study the relationship between pollution and health in an intergenerational context. Two main alternative features are introduced with respect to other studies such as Pautrel (2007). First, we consider that pollution affects the health of agents, who are forced to spend on medical care when they are elderly, rather than affecting to the workers' productivity. Second, we do not analyze long-run growth effects. We focus rather on optimal taxation and show how to design tax schemes in order to put the economy into efficient allocations.

Our characterization of the steady state shows that the more severe the pollution problem is for the economy the hight the capital and the pollution ratios are. These results differ in some terms from those obtained by John et al. (1995), who find that economies in which consumption causes greater environmental degradation accumulate less capital. This is so because in John et al.'s model agents pay taxes to maintain environmental quality when they are young and therefore an increase in degradation reduces their savings for the future. By contrast, greater environmental degradation increases health costs in our model, which are paid in old age, and thus agents have to increase savings and capital.

We show that the introduction of pollution externalities into the standard OGM yields two new results with regard to the efficiency. On the one hand, there are capital ratios above the golden rule capital ratio which may be efficient in the Pareto sense. Due to the existence of health costs associated 
with pollution, it may appear a bell shape relationship may appear between the planner's discount rate and thecapital ratio. The planner's discount rate affects the steady state capital stock through a new channel, i.e. a lower planner's discount rate implies lower pollution levels transferred to future periods, but since pollution is linked to the capital stock, it also implies lower capital stock levels transferred. This effect is opposite to the classic one according to which a lower planner's discount rate implies higher weights for future generations and thereby higher savings that transfer more capital to the future. The relative strengths of the two channels determines whether a decrease in the planner's discount rate implies higher or lower capital stock.

On the other hand, we show that the presence of pollution makes it more probable that competitive equilibrium will be dynamically inefficient. In particular, we show that if the economy accumulates more capital than the level defined above by the super golden rule ratio, there are other allocations where no generation is worse off and some are better off. For those cases, we analyze two types of tax scheme. One is based on taxing production and the other on taxing capital and wages. We show that if the two schemes are designed to place the economy in the golden rule allocation, then young and elderly agents pay less taxes (or receive more transfers) under the production scheme than under the capital-wage tax system. This implies that the production tax scheme is superior in an electoral context in which each consumer holds one vote. 


\section{References}

[1] Alberini, A., M. Cropper, T.T. Fu, A. Krupnick, J.T. Lu And W. Harrington (1997) Valuing Health Effects of Air Pollution in Developing Counties: The Case of Taiwan, Journal of Environmental Economics and Management 34, 107-126.

[2] Altonji, J.G., F. Hayashi And L. Kotlikoff (1992) Is the Extended Family Altruistically Linked? Direct Tests Using Micro Data, American Economic Review, 82(2) 1177-98.

[3] Azariadis, C. (1993) Intertemporal Economics, Blackwell Publishers, Cambridge, Massachusetts.

[4] Balcho, A. (2001) Endogenous Growth and the Possibility of Eliminating Pollution, Journal of Environmental Economics and Management 42(3), 360-373.

[5] Blanchard O.J. And S. Fischer (1989) Lectures on Macroeconomics, The MIT Press, Cambridge, Massachusetts.

[6] Bovenberg A.L. And B.J. Heijdra (1998) Environmental Tax Policy and Intergenerational Distribution, Journal of Public Economics 67, 1-24.

[7] Boyce, J.K., A.R. Klemer, P.H. Templet and C.E. Willis (1999) Power Distribution, the Environment, and Public Health: A State-Level Analysis, Ecological Economics 29, 127-140.

[8] Burmeister, E. (1980) Capital Theory and Dynamics, Cambridge University Press, Cambridge, Massachusetts.

[9] Chao, H. And S. Peck (2000) Greenhouse Gas Abatement: How Much? and Who pays? Resource and Energy Economics 67, 1-24.

[10] Diamond, P. A. (1965) National Debt in a Neoclassical Growth Model, American Economic Review 55, 1126-1150.

[11] Evans M.F. And V.K. Smith (2005) Do New Health Conditions Support Mortality-Air Pollution Effects, Journal of Environmental Economics and Management (forthcoming).

[12] Gangadharan, L. And M.R. Valenzuela (2001) Interrelationships between Income, Health and the Environment: Extending the Environmental Kuznets Curve Hypothesis, Ecological Economics 36, 513-531. 
[13] Gold, D.R., A. Litonjua, J. Schwartz, E. Lovett, A. Larson, B. Nearing, G. Allen, M. Verrier, R. Cherry and R. Verrier (2000) Ambient Pollution and Heart Rate Variability, Circulation 101, 1267-1273.

[14] Gradus, R. And S. Smulders (1996) The trade-off between environmental care and long-term growth-pollution in three prototype growth models, Journal of Economics 58(1), 25-51.

[15] Grimaud, A. (1999) Pollution Permits and Sustainable Growth in a Schumpeterian Model, Journal of Environmental Economics and Management 38(3), 249-266.

[16] Guruswamy, B, K. Kumar and N. Murthy (1977) An Overlapping Generation Model with Exhaustible Resources and Stock Pollution, Ecological Economics 21(1), 35-43.

[17] Howarth, R. (1998) An Overlapping Generations Model of ClimateEconomy Interactions, Scandinavian Journal of Economics 100(3), 57591.

[18] Howarth, R. And R. Norgaard (1992) Environmental Valuation under Sustainable Development, American Economic Review 82(2), 473-77.

[19] John, A. And R. Pecchenino (1994) An Overlapping Generation Model of Growth and the Environment, The Economic Journal 104, 1393-1410.

[20] John, A., R. Pecchenino, D. Schimmelpfennig and S. Schreft (1995) Short-lived Agents and the Long-lived Environment, Journal of Public Economics 58, 127-141.

[21] Jouvet,P.A., M. Phillippe And J.P. Vidal (2000) Intergenerational Altruism and the Environment, Scandinavian Journal of Economics 102(1), 135-50.

[22] KARP, L. (2005) Global warming and hyperbolic discounting, Journal of Public Economics 89, 261-282.

[23] Nakada, M. (2004) Does Environmental Policy Necessarily Discourage Growth? Journal of Economics 81(3), 249-268.

[24] Ono, T. (1996) Optimal Tax Schemes and the Environmental Externality, Economics Letters 53, 283-289. 
[25] Ono, T., (2002) Emission Permits on Growth and the Environmental, Environmental and Resources Economic 21, 75-87.

[26] Ono, T. and Y. Maeda (2001) Is Aging Harmful to the Environment, Environmental and Resources Economic 20(2), 113-127.

[27] Ono, T. And Y. Maeda (2002) Sustainable Development in an Aging Economy, Environment and Development Economic 7, 9-22.

[28] Ostro, B., And L. Chestnut (1998) Assessing the Health Benefits of Reducing Particular Matter Air Pollution in the United States, Environmental Research 76, 94-106.

[29] Padilla, E. (2002) Intergenerational Equity and Sustainability, Ecological Economics 41, 69-83.

[30] Pautrel, X. (2007) Environmental Policy, Health and Long-Run Economic Growth. Technical Report, Nantes Atlantique Université. http://xavier.pautrel.free.fr/pdf/REE-revision.pdf.

[31] Phelps, E. S., (1965) Second Essay on the Golden Rule of Accumulation, American Economic Review 55, 793-814.

[32] Pope, C.A. III, L.V. Richard, G.L. Eric, C.L. Andrew, E.R. Mark, E.K. Richard, S. Joel, G.M. Villegas, D.R. Gold AND W.D. Douglas (1999) Heart Rate Variability Associated with Particulate Air Pollution, American Hearth Journal 138 (5), 890-899.

[33] Quah, E. And T.L. Boon (2003) The Economic Cost of Particulate Air Pollution on Health in Singapore, Journal of Asian Economics 14, 73-90.

[34] Schwartz, J. (1995) Short Term Fluctuations in Air Pollution and Hospital Admissions of the Elderly for Respiratory Disease, Thorax $\mathbf{5 0 ( 5 ) , ~ 5 3 1 - 5 9 8 . ~}$

[35] Solow, R.M. (1986) On the Intergenerational Allocation of Natural Resources, Scandinavian Journal of Economics, 88(1), 141-149.

[36] Williams, R.C. III (2002) Environmental Tax Interaction when Pollution Affects Health or Productivity, Journal of Environmental Economics and Management 44, 261-270.

[37] Williams, R.C. III (2003) Health Effects and Optimal Environmental Taxes, Journal of Public Economics 87(3), 323-335. 
[38] World Bank (1992) World Development Report: Development and Environment. Oxford University Press.

[39] Xu, X.P., L.H. Wang, And T.H. Niu (1998) Air Pollution and its Health Effects in Beijing, Ecosystem Health 4, 199-209.

[40] Zaim, K.K. (1999) Modified GDP through Health Cost Analysis of Air Pollution: The Case of Turkey, Environmental Management 23, (2), 271-277. 


\section{Appendix}

\section{Proof of Proposition 1:}

To prove the first part of the proposition, about stability, we linearize the dynamic system (7)-(8) around the steady state. The linear approximation can be written in matrix form as

$$
\left(\begin{array}{c}
k_{t+1}-\bar{k} \\
e_{t+1}-\bar{e}
\end{array}\right)=\Phi\left(\begin{array}{c}
k_{t}-\bar{k} \\
e_{t}-\bar{e}
\end{array}\right)
$$

where $\Phi=\left(\begin{array}{cc}-\frac{s_{w} f^{\prime \prime}(\bar{k}) \bar{k}}{\Psi} & \frac{s_{e}(1-\delta)}{\Psi(1+n)} \\ -\frac{s_{w} f^{\prime \prime}(\bar{k}) \bar{k} \alpha f^{\prime}(\bar{k})}{\Psi} & \frac{\left[1+n-s_{r} f^{\prime \prime}(\bar{k})\right](1-\delta)}{\Psi(1+n)}\end{array}\right)$ and $\Psi=1+n-$ $s_{r} f^{\prime \prime}(\bar{k})-s_{e} \alpha f^{\prime}(\bar{k})$.

Following Azariadis (1993, pg 62-67), a steady state $(\bar{k}, \bar{e})$, is a sink if the following inequalities hold:

i) $|\Phi|<1$,

ii) $|\Phi|+T+1>0$,

iii) $|\Phi|-T+1>0$,

where $T$ is the trace of $\Phi$.

The strategy of the proof is to show that the stability condition imposed in Proposition 1 implies i), ii) and iii).

Proof of i): Assume that $(1+n)-s_{r} f^{\prime \prime}(\bar{k})+s_{w} f^{\prime \prime}(\bar{k}) \bar{k}-s_{e} \frac{1+n}{n+\delta} \alpha f^{\prime}(\bar{k})>0$ holds. Since $s_{w}$ and $s_{e}$ are positive and $0<\delta<1$, this condition implies

$$
(1+n)-s_{r} f^{\prime \prime}(\bar{k})+\frac{1-\delta}{1+n} s_{w} f^{\prime \prime}(\bar{k}) \bar{k}-s_{e} \alpha f^{\prime}(\bar{k})>0,
$$

and

$$
\Psi=(1+n)-s_{r} f^{\prime \prime}(\bar{k})-s_{e} \alpha f^{\prime}(\bar{k})>0 .
$$

Both inequalities imply

$$
|\Phi|=-\frac{1-\delta}{1+n} \frac{s_{w} f^{\prime \prime}(\bar{k}) \bar{k}}{\Psi}<1 .
$$

Proof of ii): Since $0<|\Phi|<1$, to prove ii) it suffices to prove that $T>0$. Notice that

$$
T=-\frac{s_{w} f^{\prime \prime}(\bar{k}) \bar{k}}{\Psi}+\frac{(1+n)-s_{r} f^{\prime \prime}(\bar{k})}{\Psi} \frac{1-\delta}{1+n}>0,
$$


because $\Psi=(1+n)-s_{r} f^{\prime \prime}(\bar{k})-s_{e} \alpha f^{\prime}(\bar{k})>0$ and therefore $(1+n)-$ $s_{r} f^{\prime \prime}(\bar{k})>0$.

Proof of iii): It is easy to show that

$|\Phi|-T+1=\frac{1}{\Psi} \frac{n+\delta}{1+n}\left[(1+n)-s_{r} f^{\prime \prime}(\bar{k})+s_{w} f^{\prime \prime}(\bar{k}) \bar{k}-s_{e} \frac{1+n}{n+\delta} \alpha f^{\prime}(\bar{k})\right]$,

which is positive under the stability condition imposed.

To prove comparative static behavior, we fully differentiate equations (9) and (10)

$$
\Gamma\left(\begin{array}{c}
d \bar{k} \\
d \bar{e}
\end{array}\right)=\Delta\left(\begin{array}{c}
d \theta \\
d \xi \\
d \lambda \\
d \alpha \\
d n \\
d \delta
\end{array}\right)
$$

where

$$
\begin{aligned}
& \Gamma=\left(\begin{array}{cc}
(1+n)-s_{r} f^{\prime \prime}(\bar{k})+s_{w} f^{\prime \prime}(\bar{k}) \bar{k} & -s_{e} \\
-\frac{1+n}{n+\delta} \alpha f^{\prime}(\bar{k}) & 1
\end{array}\right), \\
& \Delta=\left(\begin{array}{cccccc}
s_{\theta} & s_{h} & -s_{r} & 0 & 0 & 0 \\
0 & 0 & 0 & \frac{1+n}{n+\delta} f(\bar{k}) & -\frac{1-\delta}{(n+\delta)^{2}} \alpha f(\bar{k}) & -\frac{1+n}{(n+\delta)^{2}} \alpha f(\bar{k})
\end{array}\right) .
\end{aligned}
$$

Notice that $|\Gamma|$ is positive under the stability condition imposed. It is straightforward to show that

$$
\begin{array}{ll}
\frac{\partial \bar{k}}{\partial \theta}=\frac{s_{\theta}}{|\Gamma|}<0, & \frac{\partial \bar{k}}{\partial \xi}=\frac{s_{\xi}}{|\Gamma|}>0, \\
\frac{\partial \bar{k}}{\partial \lambda}=-\frac{s_{r}}{|\Gamma|} \gtrless 0, & \frac{\partial \bar{k}}{\partial \alpha}=\frac{1+n}{n+\delta} f(\bar{k}) \frac{s_{e}}{|\Gamma|}>0, \\
\frac{\partial \bar{k}}{\partial n}=-\frac{1-\delta}{(n+\delta)^{2}} \alpha f(\bar{k}) \frac{s_{e}}{|\Gamma|}<0, & \frac{\partial \bar{k}}{\partial \delta}=-\frac{1+n}{(n+\delta)^{2}} \alpha f(\bar{k}) \frac{s_{e}}{|\Gamma|}<0,
\end{array}
$$

and

$$
\frac{\partial \bar{e}}{\partial i}=\left\{\begin{array}{lcr}
\frac{1+n}{n+\delta} \alpha f^{\prime}(\bar{k}) \frac{\partial \bar{k}}{\partial i} & \text { for } \quad i=\theta, \xi, \lambda \\
\frac{(1+n)-s_{r} f^{\prime \prime}(\bar{k})+s_{w} f^{\prime \prime}(\bar{k}) \bar{k}}{s_{e}} \frac{\partial \bar{k}}{\partial i} & \text { for } \quad i=\alpha, n, \delta .
\end{array}\right.
$$

\section{Proof of Lemma 1:}

The efficient capital ratio is defined as

$$
\left[1-\frac{\alpha \xi(1+n)(1+R)}{(1+n)(1+R)-(1-\delta)}\right] f^{\prime}\left(\bar{k}^{E}\right)=(1+n)(1+R)-(1-\lambda)
$$


or, alternatively

$$
f^{\prime}\left(\bar{k}^{E}\right)=\frac{[(1+n)(1+R)-(1-\lambda)][(1+n)(1+R)-(1-\delta)]}{(1+n)(1+R)(1-\alpha \xi)-(1-\delta)} .
$$

Therefore,

$$
\frac{\partial \bar{k}^{E}}{\partial R}=f^{\prime \prime}\left(\bar{k}^{E}\right) \frac{\partial f^{\prime}\left(\bar{k}^{E}\right)}{\partial R}
$$

After some calculations the two roots of $\frac{\partial f^{\prime}\left(\bar{k}^{E}\right)}{\partial R}=0$ are found:

$$
\begin{aligned}
& R^{-}=-1+\frac{(1-\delta)-\chi^{1 / 2}}{(1+n)(1-\alpha \xi)} \\
& R^{+}=-1+\frac{(1-\delta)+\chi^{1 / 2}}{(1+n)(1-\alpha \xi)}
\end{aligned}
$$

where $\chi=(1-\delta) \alpha \xi[(1-\delta)-(1-\lambda)(1-\alpha \xi)]>0$ provided the feasibility condition holds (see footnote 17) and $R^{-}<R^{+}$.

Therefore,

$$
\frac{\partial f^{\prime}\left(\bar{k}^{E}\right)}{\partial R}=0=\frac{(1+n)^{3}(1-\alpha \xi)}{[(1+n)(1+R)(1-\alpha \xi)-(1-\delta)]^{2}}\left(1+R-R^{-}\right)\left(1+R-R^{+}\right),
$$

and given that the economy feasibility condition guarantees that $\alpha \xi<\frac{n+\delta}{1+n}<$ 1 , it can immediately be seen that

$$
\frac{\partial \bar{k}^{E}}{\partial R}=\left\{\begin{array}{ccc}
<0 & \forall & R<R^{-}<R^{+} \\
>0 & \forall & R^{-}<R<R^{+} \\
<0 & \forall & R^{-}<R^{+}<R
\end{array}\right.
$$

This means that $R^{+}$is the planner's discount rate which leads to the maximum optimal capital ratio. On the other hand,

$$
\frac{\partial R^{+}}{\partial \alpha \xi}=\frac{\frac{1}{2} \chi^{-1 / 2}(1-\alpha \xi)(1-\delta)[(1-\delta)-(1-\lambda)(1-2 \alpha \xi)]+(1-\delta)+\chi^{1 / 2}}{(1+n)(1-\alpha \xi)^{2}},
$$

which is positive provided under the feasibility condition. Therefore, $R^{+}$is a continuous and increasing function of $\alpha \xi$ with the following fixed point,

$$
\frac{\partial R^{+}}{\partial \alpha \xi}=0, \quad \Longrightarrow \quad \alpha \xi^{*}=\frac{(n+\delta)^{2}}{(1+n)^{2}-(1-\delta)(1-\lambda)}<1 .
$$


This means that $\forall \alpha \xi \in\left(\alpha \xi^{*}, 1\right)$, the maximum efficient capital ratio is achieved for $R^{+}>0$. And $\forall \alpha \xi^{\prime} \in\left(0, \alpha \xi^{*}\right)$, the maximum efficient capital ratio is achieved for $R^{+}<0$; since the central planner's discount factor is only defined in the rank $[0, \infty)$, for all values of $\alpha \xi \in\left(0, \alpha \xi^{*}\right)$, the maximum efficient capital ratio is reached for $R=0$.

\section{Proof of Proposition 2:}

Assume that the economy is initially on a stationary equilibrium path $\left(\bar{k}, \bar{e}, \bar{c}_{1}, \bar{c}_{2}\right)$. Consider the following disturbance. At time $\tau$, the capital ratio is reduced by a small amount $\varepsilon$ and consumption by old and young agents is increased by the same amount. Finally, let the capital from $\tau$ on be given by $k=\bar{k}-\varepsilon$. The utility of all generations born up to $\tau-1$ is unchanged. The generation born at $\tau-1$ is better off because the new allocation has increased its consumption in old age.

Generations born at $\tau$ and later are better off because their (current or/and future) consumption increases. This is easy to see, since from $\tau$ on the capital ratio remains constant, the stock of pollution in any future period $\tau+i, \quad \forall i \geq 0$, is given by

$$
\begin{aligned}
e_{\tau+i} & =\left(\frac{1-\delta}{1+n}\right)^{i+1} \bar{e}+\alpha \sum_{j=0}^{i}\left(\frac{1-\delta}{1+n}\right)^{j} f\left(k_{\tau+i-j}\right) \\
& =\left(\frac{1-\delta}{1+n}\right)^{i+1} \bar{e}+\alpha f(k) \frac{1+n}{n+\delta}\left[1-\left(\frac{1-\delta}{1+n}\right)^{i+1}\right] .
\end{aligned}
$$

Substituting this in the feasibility condition for a period $\tau+i, \quad \forall i \geq 0$,

$$
\begin{aligned}
f(k) & =c_{1, \tau+i}+\frac{c_{2, \tau+i}}{1+n}+(n+\lambda) k+\xi e_{\tau+i} \\
& =c_{1, \tau+i}+\frac{c_{2, \tau+i}}{1+n}+(n+\lambda) k+\xi\left(\frac{1-\delta}{1+n}\right)^{i+1} \bar{e}+\alpha \xi f(k) \frac{1+n}{n+\delta}\left[1-\left(\frac{1-\delta}{1+n}\right)^{i+1}\right] .
\end{aligned}
$$

Therefore, any change in $k$ will affect $c_{\tau+i}=c_{1, \tau+i}+\frac{c_{2, \tau+i}}{1+n}$ in the following manner,

$$
\frac{\partial c_{\tau+i}}{\partial k}=f^{\prime}(k)\left[1-\frac{1+n}{n+\delta} \alpha \xi\left(1-\left(\frac{1-\delta}{1+n}\right)^{i+1}\right)\right]-(n+\lambda) .
$$

This reallocation of capital is a Pareto improvement over the initial allocation if

$$
f^{\prime}(k)<\frac{n+\lambda}{1-\frac{1+n}{n+\delta} \alpha \xi\left[1-\left(\frac{1-\delta}{1+n}\right)^{i+1}\right]}, \quad \forall i \geq 0 .
$$


Given that the right hand side is an increasing function with $i$, this condition holds whenever it is satisfied by $i=0$, i.e. if

$$
f^{\prime}(k)<\frac{n+\lambda}{1-\alpha \xi}=f^{\prime}\left(k^{S G}\right) .
$$

Since $f^{\prime \prime}<0$, this expression means that whenever the stock of capital exceeds the super golden rule capital ratio, a reallocation of capital such as the one proposed increases the utility of the generations born at $\tau$ and later. Therefore this new allocation is a Pareto improvement over the initial allocation.

\section{Proof of Proposition 4:}

The optimal scheme follows directly on comparing equations (18)-(24) with equations (14)-(15) for the case in which $R=0$ and considering the government budget constraint. Moreover, it is easy to show that

$$
\begin{aligned}
\tau_{y}^{*} & =\left[\frac{c_{2}^{G}}{1+n}-(1+n) k^{G}\right], \\
\tau_{o}^{*} & =\left[(1+n) k^{G}-\frac{c_{2}^{G}}{1+n}-\xi e^{G}\right](1+n) .
\end{aligned}
$$

Since we are considering economies with capital overaccumulation, in the golden rule allocation it must be true that savings of young agents cannot cover the consumption and health expenses of elderly agents. Therefore $\tau_{o}$ must be a transfer (negative). However $\tau_{y}$ only is negative if the pollution is the only cause of overaccumulation, i.e. if $\frac{c_{2}^{G}}{1+n}<(1+n) k^{G}<\frac{c_{2}^{G}}{1+n}+\xi e^{G}$.

\section{Proof of Proposition 5:}

The optimal scheme follows directly on comparing equations (25)-(31) with equations (14)-(17) for the case in which $R=0$ and considering the government budget constraint. In particular, comparing equations (25) and (12) valued at $R=0$, we see that in this competitive solution an optimal tax scheme implies $\left(1+\bar{r}^{C}\right)\left(1-\tau_{k}\right)=(1+n)$. Taking this into account, equation (29) can be rewritten as

$$
\left[f^{\prime}\left(\bar{k}^{C}\right)+(1-\lambda)\right]\left(1-\tau_{k}\right)=1+n .
$$

If this expression is compared with the efficient condition given by equation (13) valued at $R=0$, the following expression must hold

$$
\left[1-\frac{\alpha \xi(1+n)}{n+\delta}\right] f^{\prime}\left(\bar{k}^{G}\right)=\left[f^{\prime}\left(\bar{k}^{G}\right)+(1-\lambda)\right]\left(1-\tau_{k}\right)-(1-\lambda) .
$$


Taking into account that in the golden rule it is satisfied that $f^{\prime}\left(\bar{k}^{G}\right)=$ $\frac{(n+\lambda)(n+\delta)}{(n+\delta)-\alpha \xi(1+n)}$, and after some manipulation the above expression implies that the capital tax rate has to be set to $\tau_{k}^{*}=\frac{(n+\lambda) \alpha \xi}{(n+\delta)-\alpha \xi(1-\lambda)}$.

$\tau_{w}$ is obtained directly by substituting equation (28) and (30) into (26). $\sigma$ is obtained straightforwardly by taking into account in equation (27) that $\left(1+\bar{r}^{C}\right)\left(1-\tau_{k}\right)=(1+n)$ is satisfied when we compare equations (25) and (12) valued at $R=0$.

On the other hand, since we are considering economies with capital overaccumulation, in the golden rule allocation it must be true that savings of young agents cannot cover the consumption and health expenses of elderly agents. Therefore $\sigma$ must be positive

On the other hand, since $n+\delta>(1+n) \alpha \xi$ (see footnote 17), $0<\tau_{k}<1$. In regard to the tax rate on wages, $\tau_{w}$, it can immediately be seen that it must be less than one, since concavity of the production function guarantees $f<f^{\prime} k$. Moreover it is easy to see that

$$
\tau_{w}=\frac{1+n}{n+\delta} \xi \alpha+\frac{\frac{c_{2}^{G}}{1+n}-(1+n) k^{G}}{f\left(k^{G}\right)-f^{\prime}\left(k^{G}\right) k^{G}},
$$

which is positive if $\frac{c_{2}^{G}}{1+n}>(1+n) k^{G}$.

\section{Proof of Proposition 6:}

It is easy to prove that the amount of taxes paid by a young agent is

$$
\begin{aligned}
T_{y}^{P} & =\left[\frac{c_{2}^{G}}{1+n}-(1+n) k^{G}\right], \\
T_{y}^{C-W} & =\left[\frac{c_{2}^{G}}{1+n}-(1+n) k^{G}+\frac{1+n}{n+\delta} \xi \alpha\left[f\left(k^{G}\right)-k^{G} f^{\prime}\left(k^{G}\right)\right]\right],
\end{aligned}
$$

with the production and capital-wage schemes, respectively. Since the production function is concave, $f\left(k^{G}\right)-k^{G} f^{\prime}\left(k^{G}\right)>0$. Therefore, $T_{y}^{P}<$ $T_{y}^{C-W}$.

The amount of taxes paid by an elderly agent is

$$
\begin{aligned}
T_{o}^{P} & =\left[\frac{c_{2}^{G}}{1+n}-(1+n-\xi) k^{G}\right](1+n), \\
T_{o}^{C-W} & =-(1+n) T_{y}^{C-W}=-\left[\frac{c_{2}^{G}}{1+n}-(1+n-\xi) k^{G}+k^{G}\left[f^{\prime}\left(k^{G N}\right)-f^{\prime}\left(k^{G}\right)\right]\right](1+n),
\end{aligned}
$$

with the production and capital-wage schemes, respectively. $T_{o}^{P}<T_{o}^{C-W}$ because $f^{\prime}\left(k^{G N}\right)<f^{\prime}\left(k^{G}\right)$. 